\title{
Identification of the GTPase superfamily in Mycoplasma synoviae and Mycoplasma hyopneumoniae
}

\author{
Clayton Luiz Borges, Juliana Alves Parente, Maristela Pereira and Célia Maria de Almeida Soares \\ Laboratório de Biologia Molecular, Instituto de Ciências Biológicas, Universidade Federal de Goiás, \\ Goiânia, Goiás, Brazil.
}

\begin{abstract}
Mycoplasmas are the smallest known prokaryotes with self-replication ability. They are obligate parasites, taking up many molecules of their hosts and acting as pathogens in men, animals, birds and plants. Mycoplasma hyopneumoniae is the infective agent of swine mycoplasmosis and Mycoplasma synoviae is responsible for subclinical upper respiratory infections that may result in airsacculitis and synovitis in chickens and turkeys. These highly infectious organisms present a worldwide distribution and are responsible for major economic problems. Proteins of the GTPase superfamily occur in all domains of life, regulating functions such as protein synthesis, cell cycle and differentiation. Despite their functional diversity, all GTPases are believed to have evolved from a single common ancestor. In this work we have identified mycoplasma GTPases by searching the complete genome databases of Mycoplasma synoviae and Mycoplasma hyopneumoniae, J (non-pathogenic) and 7448 (pathogenic) strains. Fifteen ORFs encoding predicted GTPases were found in M. synoviae and in the two strains of M. hyopneumoniae. Searches for conserved G domains in GTPases were performed and the sequences were classified into families. The GTPase phylogenetic analysis showed that the subfamilies were well resolved into clades. The presence of GTPases in the three strains suggests the importance of GTPases in 'minimalist' genomes.
\end{abstract}

Key words: Mycoplasma, GTPase superfamily, genome.

Received: April 12, 2006; Accepted: October 10, 2006.

\section{Introduction}

Mycoplasmas are a genus of obligate parasites belonging to the Mollicutes class, the smallest known prokaryotes with self-replication ability (Razin et al., 1998). They present a very small genome evolved to the minimalist status by losing non-essential genes, including those involved in cell wall synthesis, as well those related to catabolic and metabolic pathways (Himmelreich et al., 1996). The two species, Mycoplasma hyopneumoniae and Mycoplasma synoviae, are responsible for significant economic impact on animal production. M. hyopneumoniae is the infective agent of swine mycoplasmosis (DeBey and Ross, 1994), which increases the susceptibility to secondary infections (Ciprian et al., 1988). M. synoviae is responsible for subclinical upper respiratory infections, but may also result in airsacculitis and synovitis in chickens and turkeys (Kleven, 1997; Allen et al., 2005).

Many crucial functions for life are provided by a single versatile mechanism that has evolved to fulfill many

Send correspondence to Célia Maria de Almeida Soares. Laboratório de Biologia Molecular, Instituto de Ciências Biológicas, sala 206, Universidade Federal de Goiás, 74.001-970 Goiânia, Goiás, Brazil. E-mail: celia@icb.ufg.br. roles. A prime example is the GTPase superfamily of proteins that occurs in all domains of life, regulating functions such as protein synthesis, cell cycle and differentiation (Bourne et al., 1990). Despite this extraordinary functional diversity, all GTPases are believed to have evolved from a single common ancestor, a fact which resulted in the conservation of their action mechanism, of the core structure and of sequence motifs (Bourne, 1995).

GTPases are often described as molecular switch proteins because of their particular mode of action. Each GTPase specifically binds and hydrolyzes GTP in a cyclic mechanism that activates and inactivates the GTPase protein (Bourne et al., 1991). In this cycle, a GTPase passes through three conformational states. Initially, the GTPase is inactive and is not bound to any nucleotide. After binding GTP, the protein becomes active and changes its conformation, and as such its affinity to effector molecules or other enzymes. GTP is then hydrolyzed simultaneously, with an effect being generated in the GTPase target. Subsequently, GDP is released from the inactive GTPase, returning the protein to the empty state. This cycle allows the active GTPase to interact periodically with a target and, in this 
way, to act as a timed switch in the cell (Bourne et al., 1990).

That cyclic reaction usually involves several other factors that either catalyze the hydrolysis step of the GTPase cycle or catalyze the release of bound GDP from the inactive state of the GTPase (Bourne, 1995). Each GTPase cycle appears to be unique. The rate of switch turnover is dependent on specific interaction factors, as well as on the intrinsic properties of each GTPase. Additionally, some GTPases interact with many different effectors and targets and, in that way, can coordinate cellular responses (Bourne et al., 1990; Bourne, 1995). A core domain that is able to bind either GTP or GDP confers the characteristic switch mechanism of GTPases. The folding of this domain is a defining feature of GTPases (Jurnak et al., 1990). In fact, X-ray crystallography of diverse GTPases shows that the folding of this G-domain is nearly invariant throughout the GTPase superfamily. GTPases can consist solely of the G-domain or may have additional domains on the aminoand carboxyl-terminal ends of the proteins (Sprang, 1997).

Due to the importance of the mycoplasmas, complete genome projects have been reported in the last years (Himmelreich et al., 1996; Hutchison et al. 1999; Glass et al., 2000; Chambaud et al., 2001; Papazisi et al., 2003; Sasaki et al., 2002; Jaffe et al., 2004; Minion et al., 2004; Westberg et al., 2004). Complete genomes of M. synoviae (strain 53), M. hyopneumoniae pathogenic strain (7448) and non-pathogenic strain (J [ATCC25934]) were recently described (Vasconcelos, et al., 2005) and the data are available in databases. The objective of this work is the identification and classification of the GTPase superfamily in the three complete genomes of $M$. synoviae strain 53 and $M$. hyopneumoniae (strains J and 7448).

\section{Material and Methods}

By using data from the complete genome of $M$. synoviae and M. hyopneumoniae, strains J and 7448 associated to BLAST search tools we have identified 15 ORFs encoding GTPase superfamily homologs in M. synoviae, as well as 15 ORFs in both strains of M. hyopneumoniae. Classification of the GTPase families and their putative function has been performed by using Pfam interface and InterPro homepage. Search for G-domains in mycoplasma GTPases was performed by alignment of described Escherichia coli GTPases sequences (Caldon et al., 2001) with those of M. synoviae and M. hyopneumoniae (strains $\mathrm{J}$ and 7448). Multiple sequence alignments were generated using the ClustalX 1.81 software (Thompson et al., 1997).

The phylogenetic relationships within the GTPase superfamily were inferred from all 33 sequences from $M$. synoviae strain 53 and $M$. hyopneumoniae strains $\mathrm{J}$ and 7448. A phylogenetic tree was constructed by multiple sequence alignments using the Clustal $\mathrm{X}$ program and visualized by using the Tree View software. Trees were constructed by using the neighbor-joining method (Saitou and Nei, 1987). Robustness of branches was estimated by using 100 bootstrap replicates.

\section{Results and Discussion}

\section{Structural analysis of the GTPases superfamily}

Searches for GTPases performed on M. synoviae and M. hyopneomoniae strains J and 7448 genome databases revealed the presence of 15 GTPase orthologs. These GTPases were classified into subfamilies, and the results are shown in Table 1. ORFs were classified as belonging to the Elongation factor, the Era, the FtsY/Ffh and the $\mathrm{Obg} / \mathrm{YchF}$ subfamilies, or were annotated as unclassified proteins related to GTPases or GTP binding proteins.

Searches for the G-domain, described in all GTPase subfamilies, was performed by using the deduced protein sequences encoded by the identified ORFs presented in Table 1. Figure 1 presents the alignment of the G1-G4 motifs of the cited GTPases. The G-domain is divided into four $\mathrm{G}$ motifs: G1 (G/AXXXXGKT/S), G2 (not conserved), G3 (DXXG) and G4 (NKXD) sequence motifs, where X denotes any amino acid (Caldon, et al., 2001). The G1, G2 and G3 motifs were found in all mycoplasma GTPase subfamilies (Figure 1). The G4 motif was found in the EF-G, EF-Tu, IL-2, LepA, Era, EngA, ThdF/TmE, and OBG subfamilies. In the YchF, FtsY and Ffh subfamilies, the region of the G4 motif, although present, was not well conserved (Figure 1).

Functions ascribed to G-motifs include the mediation of interactions with the guanine nucleotides and effector proteins. It has been suggested that G1, G3 and G4 motifs could have evolved to bind and hydrolyze guanosine triphosphate and also for interacting with the cofactor $\mathrm{mg}^{2+}$ (Bourne et al., 1991). The non conserved G2 motif is described as the effector domain that undergoes a conformational change necessary for GTPase function (Bourne, et al., 1995, Sprang, 1997).

\section{Elongation factor subfamily}

The elongation factor subfamily (EF) is composed of the Elongation factor - G (EF-G), Elongation factor-TU (EF-TU), Initiation factor-2 (IF-2) and GTP-binding protein LepA (LepA), (Caldon, et al. 2001). The EF family from bacteria is composed of multidomain GTPases with essential functions in the elongation and initiation phases of translation. EF-Tu catalyzes binding of aminoacyl-tRNA to the ribosomal A-site, while EF-G catalyses the translocation of peptidyl-tRNA from the A-site to the P-site (Rodnina et al., 2000; Nilsson and Nissen, 2005). The initiation factor-2 (IF-2) may be involved in introducing the initiator tRNA into the translation machinery and in performing the first step in the peptide chain elongation cycle (Kyrpides and Woese, 1998). ORFs encoding all elongation factor members were present in $M$. synoviae and $M$. hyopneumoniae J and 7448 (Table 1). All G1-4 motifs were 
Table 1 - ORFs encoding GTPases and GTP binding proteins from M. synoviae strain 53 and M. hyopneumoniae strains J and 7448, with putative functions.

\begin{tabular}{|c|c|c|c|c|c|}
\hline \multirow[t]{2}{*}{ GTPase Family } & \multirow[t]{2}{*}{ ORF Product } & \multirow{2}{*}{$\begin{array}{l}\text { EC /Cellular process } \\
\text { involvement }\end{array}$} & \multicolumn{3}{|c|}{ ORFs encoding GTPases found in Mycoplasmas } \\
\hline & & & $\begin{array}{l}\text { Mycoplasma } \\
\text { synoviae } 53\end{array}$ & $\begin{array}{c}\text { Mycoplasma } \\
\text { hyopneumoniae }-J\end{array}$ & $\begin{array}{c}\text { Mycoplasma } \\
\text { hyopneumoniae }-7448\end{array}$ \\
\hline \multicolumn{6}{|c|}{ Elongation factor subfamily } \\
\hline EF-G & Elongation factor EF-G & 3.6.1.48 / protein biosynthesis & MS0047 & MHJ0071 & MHP0075 \\
\hline EF-TU & Elongation factor $\mathrm{Tu}$ & 3.6.1.48 / protein biosynthesis & MS0667 & MHJ0524 & MHP0523 \\
\hline IF-2 & $\begin{array}{l}\text { Translation initiation factor } \\
\text { IF-2 }\end{array}$ & - / Binding / protein biosynthesis & MS0686 & MHJ0585 & MHP0584 \\
\hline LepA & GTP-binding protein LepA & - / Protein biosynthesis & MS0489 & MHJ0069 & MHP0073 \\
\hline \multicolumn{6}{|l|}{ Era subfamily } \\
\hline Era & GTP-binding protein Era & - / ATP Binding / nucleic acid binding & MS0387 & MHJ0152 & MHP0156 \\
\hline EngA & GTP-binding protein EngA & - / 70s ribosome stabilization & MS0142 & MHJ0066 & MHP0070 \\
\hline ThdF/TrmE & $\begin{array}{l}\text { Thiophene and furan oxida- } \\
\text { tion protein ThdF }\end{array}$ & $\begin{array}{l}\text { - / tRNA processing - indirect Ribo- } \\
\text { some function }\end{array}$ & MS0362 & MHJ0205 & MHP0209 \\
\hline \multicolumn{6}{|c|}{ FtsY/Ffh subfamily } \\
\hline FtsY & Cell division protein FtsY & - / Cell division & MS0145 & MHJ0008 & MHP0008 \\
\hline Ffh & $\begin{array}{l}\text { Signal recognition parti- } \\
\text { cle, subunit FFH/SRP54 }\end{array}$ & - / Protein targeting to membrane & MS0021 & MHJ0053 & MHP0057 \\
\hline \multicolumn{6}{|l|}{ Obg and YchF } \\
\hline OBG & GTP-binding protein Obg & - / Ribosome maturation. & MS0168 & MHJ0037 & MHP0041 \\
\hline YchF & GTP-binding protein $\mathrm{YchF}$ & - / Putative ATP Binding & MS0663 & MHJ0284 & МНР0293 \\
\hline Unclassified & $\begin{array}{l}\text { GTP-binding protein } \\
\text { Cell division protein FtsZ } \\
\text { Probable GTPase EngC } \\
\text { Putative GTP-binding protein }\end{array}$ & $\begin{array}{l}\text { - / Cell division } \\
\text { - / Cell division } \\
\text { EC 3.6.1.- / unknown } \\
\text { - / ATP Binding }\end{array}$ & $\begin{array}{l}\text { MS0650 - YihA } \\
\text { MS0340 - FtsZ } \\
\text { MS0120 - EngC } \\
\text { MS0664 - YlqF }\end{array}$ & $\begin{array}{l}\text { MHJ0446 - YihA } \\
\text { MHJ0406 - FtsZ } \\
\text { MHJ0148 - EngC } \\
\text { MHJ0083 - YlqF }\end{array}$ & $\begin{array}{l}\text { MHP0449 - YihA } \\
\text { MHP0393 - FtsZ } \\
\text { MHP0152 - EngC } \\
\text { MHP0087 - YlqF }\end{array}$ \\
\hline
\end{tabular}

found in the ORFs encoding EF GTPases from both mycoplasma species (Figure 1), suggesting that the proteins can be functional in these organisms. Two truncated hypothetical EF-G proteins were also found in the $M$. synoviae genome. The ORFs present high homology to the 3 ' region of the complete EF-G ORF found in this organism, suggesting that they are not functional genes, in accordance with the 'minimal genome' characteristic of mycoplasmas.

\section{Era subfamily}

This family is comprised of the GTP binding protein ERA (ERA), the GTP binding protein EngA (EngA), as well as the Thiophene and furam oxidation protein (ThdF). Both M. synoviae and M. hypneumoniae (J and 7448) present ORFs related to the Era subfamily. The Era member of the Era subfamily is an essential GTPase that probably regulates the cell cycle (Gollop and March, 1991; Britton et al., 1998) and is involved in regulating carbon (Lerner and Inouye, 1991) and nitrogen (Powell et al., 1995) metabolism. A second member of this group, EngA, has been suggested to be essential for growth in Neisseria gonorrhoeae (Mehr et al., 2000). ThdF may be involved in tRNA modification and in the direct or indirect regulation of ribosome function (Caldon, et al., 2001). The presence of all Era subfamily members (Table 1) with all G1-G4 motifs (Figure 1) in M. synoviae and M. hyopneumoniae (J and 7448) suggests that those ORF products are active and play biological functions in the analyzed organisms.

\section{FtsY/Ffh subfamily}

The FtsY/Ffh subfamily is represented by the cell division protein FtsY, termed FtsY, and by the signal recognition particle FFH/SRP54, termed Ffh. ORFs encoding for the two proteins of this subfamily have been reported in the M. synoviae strain 53 and M. hyopneumoniae strains $\mathrm{J}$ and 7448 (Table 1). The G1-G3 motifs were found in the deduced amino acid sequences for Fts $\mathrm{Y}$ and Ffh of $M$. synoviae strain 53 and $M$. hyopneumoniae strains $\mathrm{J}$ and 7448, when compared with $E$. coli $\mathrm{FtsY} / \mathrm{Ffh}$ sequences (Figure 1). The sequence corresponding to the G4 motif was found in the three analyzed mycoplasmas, even though this motif was not well conserved (NKXD). The amino acids $\mathrm{K}$ and $\mathrm{D}$ are present in mycoplasma Fts $\mathrm{Y}$ and Ffh sequences in comparison to the E. coli ortholog predicted proteins. These proteins are described as essential to E. coli since $\mathrm{Ffh} / \mathrm{SRP}$ mutants present a lethal phenotype and SRP subunit mutants present growth defects (Lu, et al., 2001).

\section{OBG and YchF subfamily}

The comparative analysis of $M$. synoviae strain $53, M$. hyopneumoniae (strains J and 7448) showed the presence of the same ortholog ORFs encoding OBG and YchF proteins (Table 1). G1-G3 motifs were found in all ORF products. The G4 motif was found in the OBG member, but not in the YchF ORF product (Figure 1). Similarly, this motif was also not found well conserved in the E. coli YchF protein. 

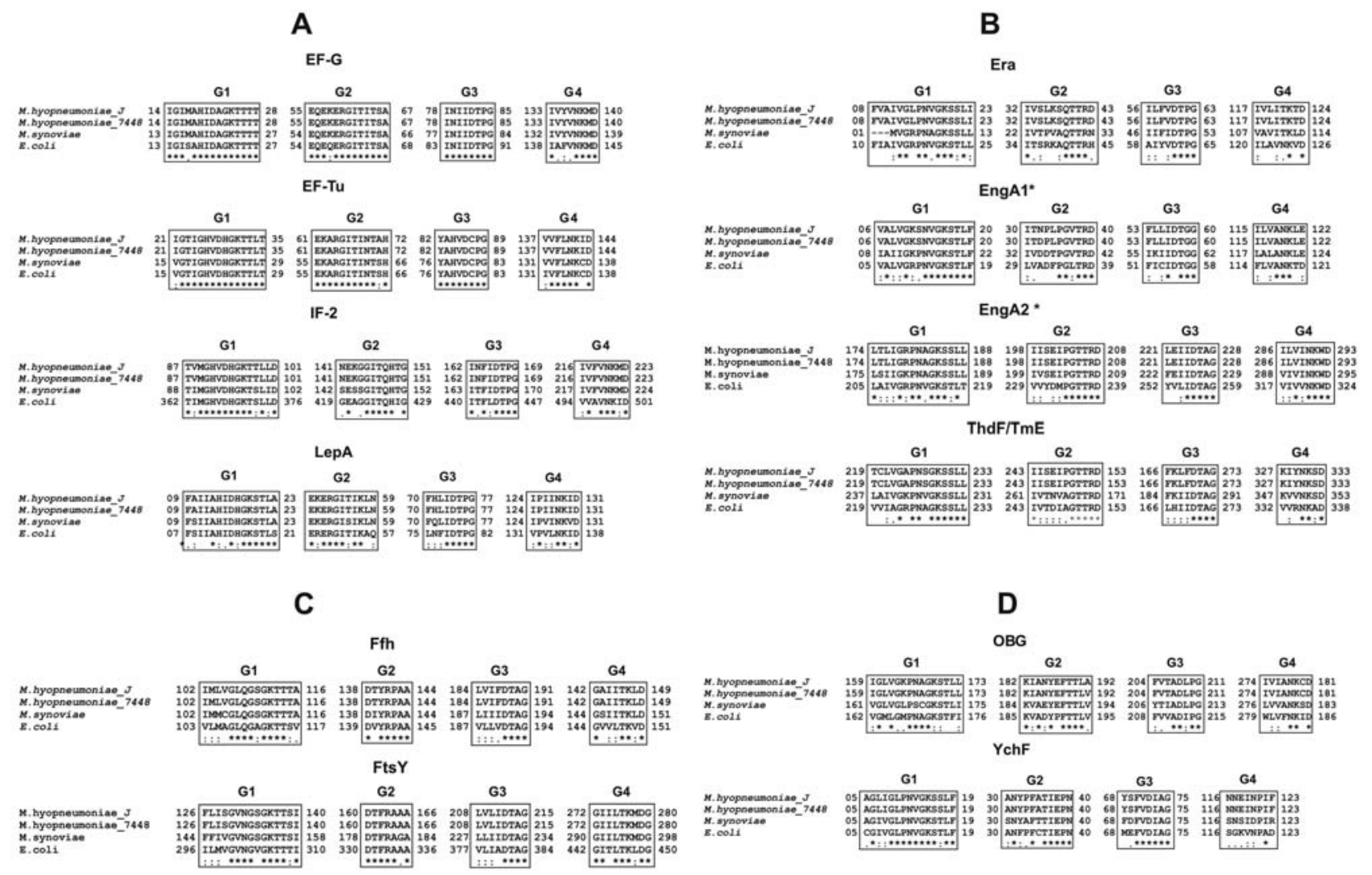

Figure 1 - Alignment of G1, G2, G3 and G4 motifs of the GTPase subfamilies. Panel A: Elongation factor subfamily. Panel B: Era subfamily. Panel C: FtsY/Ffh subfamily. Panel D: OBG YchF subfamily. The sequences used in the alignment are listed in Table 1 and were obtained from: $M$. hyopneumoniae J (Mycoplasma hyopneumoniae J GenBank accession number NC-007295), M. hyopneumoniae 7448 (Mycoplasma hyopneumoniae 7448, GenBank accession number NC-007332), M. synoviae (Mycoplasma synoviae GenBank accession number NC-007294) and E. coli (Escherichia coli, GenBank accession number NC-000913). The positions of the G1-G4 motifs were obtained by comparison with the most highly conserved regions of E. coli orthologs.

*EngA1 and EngA2 refer to the two different G-domains found in all EngA orthologues.

The function of the OBG subfamily remains elusive, although there is evidence for its involvement in the initiation of chromosome replication (Kok et al., 1994), in bacterial sporulation (Trach and Hoch, 1989; Vidwans et al., 1995), and in the activation of a transcription factor that controls the general stress response (Scott and Haldenwang, 1999). The YchF members of the OBG/YchF subfamily are also distributed in all domains of life, (Mittenhuber, 2001), but the biological function of this protein has not been elucidated.

\section{Unclassified GTPases}

The GTPases found in the genomes of mycoplasmas which were not classified as belonging to one of the 11 universally conserved bacterial GTPases (Caldon, et al., 2001) were described here as unclassified. Four ORFs from $M$. synoviae strain 53 and $M$. hyopneumoniae strains $\mathrm{J}$ and 7448 were identified in this group: EngC, YlqF, FtsZ and YihA. The E. coli ortholog EngC is a GTPase with a predicted role as a regulator of translation (Daigle and Brown, 2004). The putative GTP binding protein YlqF is described as necessary for growth of Streptococcus pneumoniae and
Staphylococcus aureus and may be involved in ribosomal assembly (Zalacain et al., 2003).

The cell division protein FtsZ was also found in $M$. synoviae strain 53 and $M$. hyopneumoniae strains $\mathrm{J}$ and 7448. This protein appears to act at the earliest step in cell septation and is required at the final steps of cytokinesis (Ma, et al., 1996; Jensen, et al., 2005). The GTPase YihA has been described as an essential gene of the bacterial 'minimal genome', even though it seems to be dispensable in some organisms, as described for Mycobacterium tuberculosis, Chlamydia trachomatis, Treponema pallidum, Borrelia burgdorferi and Synechocystis sp. (Dassain et al., 1999).

\section{GTPase amino acid sequence relationships}

To visualize the amino acid sequence relationship of Mycoplasma GTPase subfamilies, a phylogenetic tree was constructed by using the neighbour-joining method (Saitou and Nei, 1987). A total of 33 deduced amino acid sequences encoding GTPases from M. synoviae, M. hyopneumoniae $\mathbf{J}$ and $M$. hyopneumoniae 7448 were aligned using the CLUSTAL X program (Thompson et al., 1997). Robust- 


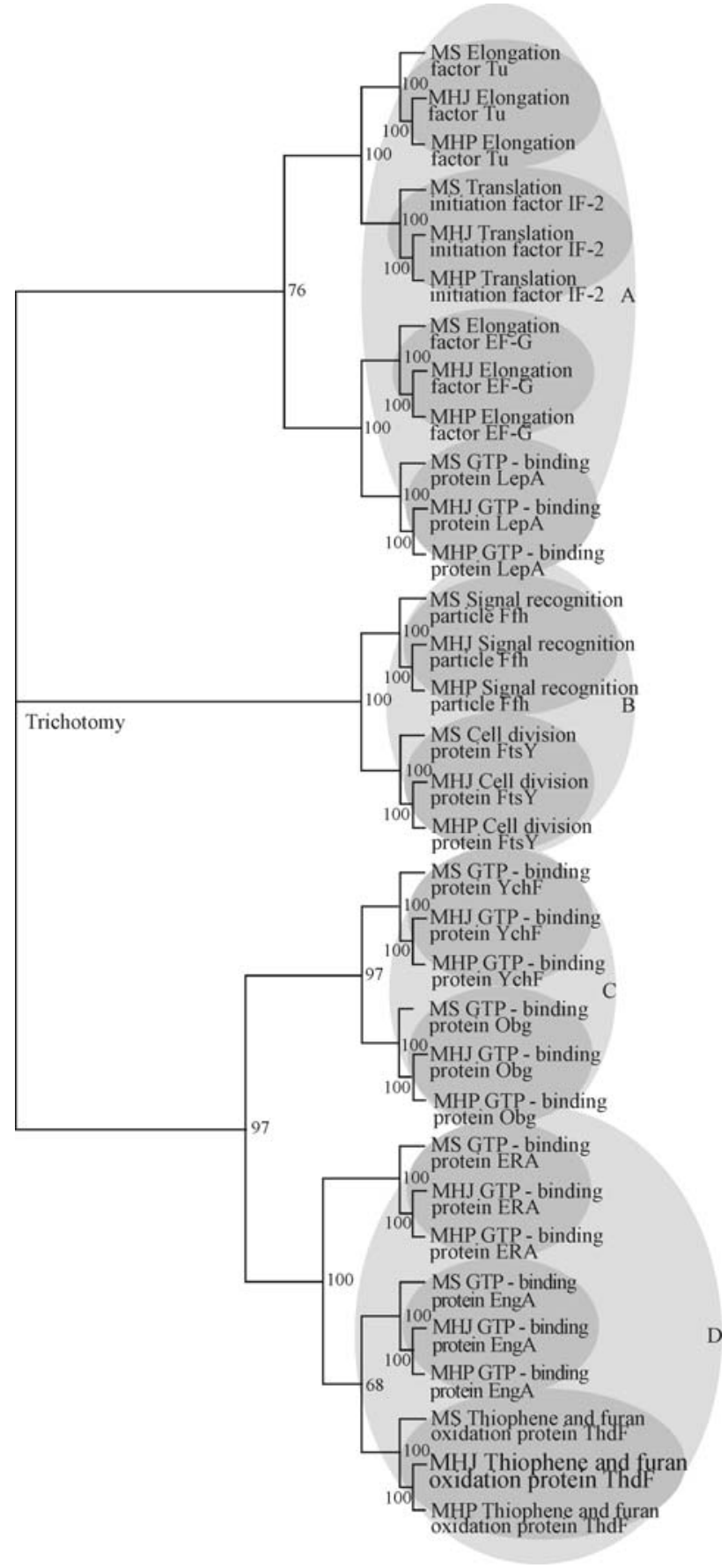

Figure 2 - Amino acid sequence relationship of the GTPase superfamily. (A) Elongation factor subfamily. (B) FtsY/Ffh subfamily. (C) OBG/YchF subfamily. (D) Era subfamily. The numbers on the branches are bootstrap values obtained with 100 replications. Members of each family are described as MS for M. synoviae strain 53, MHJ for M. hyopneumoniae strain J and MHP for M. hyopneumoniae strain 7448.

ness of branches was estimated by using 100 bootstrap replicates. By using the Tree View software a deduced phylogeny was visualized and is shown in Figure 2. A close relationship among amino acid sequences of proteins which belong to the same subfamily can be observed in the three Mycoplasma species. GTPases that have similar func- tions were clustered into the same clade, suggesting a metabolic conservation in reactions involving GTPases. The bootstrap values reveal the high homology among the subfamilies of proteins of $M$. synoviae strain 53 and $M$. hyopneumoniae strains $\mathrm{J}$ and 7448. GTPases are classified into subfamilies based on the presence of different G-domains (G1, G2, G3 and G4). Since unclassified GTPases do not present conserved G-domains, and were not classified by Caldon et al. (2001), they were not included in our phylogenetic analysis.

\section{Concluding Remarks}

The GTPase superfamily, present in all domains of life, is related to many functions such as protein synthesis, cell cycle and differentiation. The presence of orthologs for all the subfamily members described in prokaryotes in the complete genome of $M$. synoviae and M. hyopneumoniae strains $\mathrm{J}$ and 7448 , evidences the essential functions of GTPases in these 'minimalist' organisms.

\section{Acknowledgments}

This work was carried out int the context of the Brazilian National Genome Program (Southern Network for Genome Analysis and Brazilian National Genome Project Consortium) with funding provided by $\mathrm{MCT} / \mathrm{CNPq}$ and SCT/FAPERGS (RS).

\section{Abbreviations}

EF-G (Elongation factor G).

EF-TU (Elongation factor Tu).

IF-2 (Translation initiation factor 2).

MHJ (Mycoplasma hyopneumoniae strain J).

MHP (Mycoplasma hyopneumoniae strain 7448).

MS (Mycoplasma synoviae strain 53).

ThdF (Thiophene and furan oxidation protein).

\section{References}

Allen JL, Noormohammadi AH and Browning GF (2005) The vlhA loci of Mycoplasma synoviae are confined to a restricted region of the genome. Microbiology 3:935-940.

Bourne HR (1995) GTPases: A family of molecular switches and clocks. Philos Trans R Soc Lond B Biol Sci 1329:283-289.

Bourne HR, Sanders DA and McCormick F (1990) The GTPase superfamily: A conserved switch of diverse cell functions. Nature 348:125-132.

Bourne HR, Sanders DA and McCormick F (1991) The GTPase superfamily: Conserved structure and molecular mechanism. Nature 6305:117-127.

Britton RA, Powell BS, Dasgupta S, Sun Q, Margolin W, Lupski JR and Court DL (1998) Cell cycle arrest in Era GTPase mutants - A potential growth rate-regulated checkpoint in Escherichia coli. Mol Microbiol 27:739-750.

Caldon CE, Yoong P and Marc PE (2001) Evolution of a molecular switch: Universal bacterial GTPases regulate ribosome function. Mol Microbiol 41:289-297. 
Chambaud I, Heilig R, Ferris S, Barbe V, Samson D, Galisson F, Moszer I, Dybvig K, Wroblewski H, Viari A, Rocha EP and Blanchard A (2001) The complete genome sequence of the murine respiratory pathogen Mycoplasma pulmonis. Nucleic Acids Res 29:2145-2153.

Ciprian A, Pijoan C, Cruz T, Camacho J, Tortora J, Colmenares G, Lopez-Revilla R and de la Garza M (1988) Mycoplasma hyopneumoniae increases the susceptibility of pigs to experimental Pasteurella multocida pneumonia. Can J Vet Res 52:434-438.

Daigle DM and Brown ED (2004) Studies of the interaction of Escherichia coli $\mathrm{YjeQ}$ with the ribosome in vitro. J Bacteriol 186:1381-1387.

Dassain M, Leroy A, Colosetti L, Carole S and Bouche JP (1999) A new essential gene of the 'minimal genome' affecting cell division. Biochimie 81:889-895.

DeBey MC and Ross RF (1994) Ciliostasis and loss of cilia induced by Mycoplasma hyopneumoniae in porcine tracheal organ cultures. Infect Immun 62:5312-5318.

Glass JI, Lefkowitz EJ, Glass JS, Heiner CR, Chen EY and Cassell GH (2000) The complete sequence of the mucosal pathogen Ureaplasma urealyticum. Nature 407:757-762.

Gollop N and March PE (1991) A GTP-binding protein (Era) has an essential role in growth rate and cell cycle control in Escherichia coli. J Bacteriol 173:2265-2270.

Himmelreich R, Hilbert H, Plagens H, Pirkl E, Li BC and Herrmann R (1996) Complete sequence analysis of the genome of the bacterium Mycoplasma pneumoniae. Nucleic Acids Res 24:4420-4449.

Hutchison CA, Peterson SN, Gill SR, Cline RT, White O, Fraser CM, Smith HO and Venter JC (1999) Global transposon mutagenesis and a minimal Mycoplasma genome. Science 286:2165-2169.

Jaffe JD, Stange-Thomann N, Smith C, DeCaprio D, Fisher S, Butler J, Calvo S, Elkins T, FitzGerald MG, Hafez N, Kodira CD, Major J, Wang S, Wilkinson J, Nicol R, Nusbaum C, Birren B, Berg HC and Church GM (2004) The complete genome and proteome of Mycoplasma mobile. Genome Res. 14:1447-1461.

Jensen SO, Thompson LS and Harry EJ (2005) Cell division in Bacillus subtilis: FtsZ and FtsA association is Z-ring independent, and FtsA is required for efficient midcell Z-Ring assembly. J Bacteriol 18:6536-6544.

Jurnak F, Heffron S, Schick B and Delaria K (1990) Three-dimensional models of the GDP and GTP forms of the guanine nucleotide domain of Escherichia coli elongation factor Tu. Biochim Biophys Acta 1050:209-214.

Kleven SH (1997) Mycoplasma synoviae infection. In: Calnek BW, Barnes HJ, Beard CW, McDouglas LR and Saif YM (eds) Diseases of Poultry. University Press, Ames, pp 220-228.

Kok J, Trach KA and Hoch JA (1994) Effects on Bacillus subtilis of a conditional lethal mutation in the essential GTP binding protein Obg. J Bacteriol 176:7155-7160.

Kyrpides NC and Woese CR (1998) Archaeal translation initiation revisited: The initiation factor 2 and eukaryotic initiation factor 2B alpha-beta-delta subunit families. Proc Natl Acad Sci USA 95:3726-3730.

Lerner CG and Inouye M (1991) Pleiotropic changes resulting from depletion of Era, an essential GTP-binding protein in Escherichia coli. Mol Microbiol 5:951-957.
Lu Y, Qi HY, Hyndman JB, Ulbrandt ND, Teplyakov A, Tomasevic N and Bernstein HD (2001) Evidence for a novel GTPase priming step in the SRP protein targeting pathway. EMBO J 20:6724-6734.

Ma X, Ehrhardt DW and Margolin W (1996) Colocalization of cell division proteins FtsZ and FtsA to cytoskeletal structures in living Escherichia coli cells by using the green fluorescent protein. Proc Natl Acad Sci USA 93:12998-13003.

Mehr IJ, Long CD, Serkin CD and Seifert HS (2000) A homologue of the recombination-dependent growth gene, $\mathrm{rdgC}$, is involved in gonococcal pilin antigenic variation. Genetics 154:523-532.

Minion FC, Lefkowitz EJ, Madsen ML, Cleary BJ, Swartzell SM and Mahairas GG (2004) The genome sequence of Mycoplasma hyopneumoniae strain 232, the agent of swine mycoplasmosis. J Bacteriol 186:7123-7133.

Mittenhuber G (2001) Comparative genomics of prokaryotic GTP-binding proteins (the Era, Obg, EngA, ThdF (TrmE), YchF and Yih families) and their relationship to eukaryotic GTP-binding proteins (the DRG, ARF, RAB, RAN, RAS, and RHO families). J Mol Microbiol Biotechnol 3:21-35.

Nilsson J and Nissen P (2005) Elongation factors on the ribosome. Curr Opin Struct Biol 15:349-354.

Papazisi L, Gorton TS, Kutish G, Markham PF, Browning GF, Nguyen DK, Swartzell S, Madan A, Mahairas G and Geary SJ (2003) The complete genome sequence of the avian pathogen Mycoplasma gallisepticum strain R (low). Microbiology 149:2307-2316.

Powell BS, Court DL, Inada T, Nakamura Y, Michotey V, Cui X, Reizer A, Saier MH Jr and Reizer J (1995) Novel proteins of the phosphotransferase system encoded within the rpoN operon of Escherichia coli : Enzyme IIA-Ntr affects growth on organic nitrogen and the conditional lethality of an era-ts mutant. J Biol Chem 270:4822-4839.

Razin S, Yogev D and Naot Y (1998) Molecular biology and pathogenicity of mycoplasmas. Microbiol Mol Biol Rev 62:1094-1156.

Rodnina MV, Stark H, Savelsbergh A, Wieden HJ, Mohr D, Matassova NB, Peske F, Daviter T, Gualerzi CO and Wintermeyer W(2000) GTPase mechanisms and functions of translation factors on the ribosome. Biol Chem 381:377-387.

Saitou N and Nei M (1987) The neighbor-joining method: A new method for reconstructing phylogenetic trees. Mol Biol Evol 4:406-425.

Sasaki Y, Ishikawa J, Yamashita A, Oshima K, Kenri T, Furuya K, Yoshino C, Horino A, Shiba T, Sasaki T and Hattori M (2002) The complete genomic sequence of Mycoplasma penetrans, an intracellular bacterial pathogen in humans. Nucleic Acids Res 30:5293-5300.

Scott JM and Haldenwang WG (1999) Obg, an essential GTP binding protein of Bacillus subtilis, is necessary for stress activation of transcription factor Sigma(B). J Bacteriol 181:4653-4660.

Sprang SR (1997) G proteins, effectors and GAPs: Structure and mechanism. Curr Opin Struct Biol 7:849-856.

Thompson JD, Gibson TJ, Plewniak F, Jeanmougin F and Higgins DG (1997) The ClustalX windows interface: Flexible strategies for multiple sequence alignment aided by quality analysis tools. Nucleic Acids Res 24:4876-4882. 
Trach K and Hoch JA (1989) The Bacillus subtilisspo0B stage 0 sporulation operon encodes an essential GTP binding protein. J Bacteriol 171:1362-1371.

Vasconcelos AT, Ferreira HB, Bizarro CV, Bonatto SL, Carvalho MO, Pinto PM, Almeida DF, Almeida LG, Almeida R, Alves-Filho L, Assuncao EN, Azevedo VA, Bogo MR, Brigido MM, Brocchi M, Burity HA, Camargo AA, Camargo SS, Carepo MS, Carraro DM, de Mattos Cascardo JC, Castro LA, Cavalcanti G, Chemale G, Collevatti RG, Cunha CW, Dallagiovanna B, Dambros BP, Dellagostin OA, Falcao C, Fantinatti-Garboggini F, Felipe MS, Fiorentin L, Franco GR, Freitas NS, Frias D, Grangeiro TB, Grisard EC, Guimaraes CT, Hungria M, Jardim SN, Krieger MA, Laurino JP, Lima LF, Lopes MI, Loreto EL, Madeira HM, Manfio GP, Maranhao AQ, Martinkovics CT, Medeiros SR, Moreira MA, Neiva M, Ramalho-Neto CE, Nicolas MF, Oliveira SC, Paixao RF, Pedrosa FO, Pena SD, Pereira M, Pereira-Ferrari L, Piffer I, Pinto LS, Potrich DP, Salim AC, Santos FR, Schmitt R, Schneider MP, Schrank A, Schrank IS, Schuck AF, Seuanez HN, Silva DW, Silva R, Silva SC, Soares CM, Souza KR, Souza RC, Staats CC, Steffens MB, Teixeira SM, Urmenyi TP, Vainstein MH, Zuccherato LW, Simpson AJ and Zaha A (2005) Swine and Poultry Pathogens: The Complete Genome Sequences of Two Strains of Mycoplasma hyopneumoniae and a Strain of Mycoplasma synoviae. J Bacteriol. 15:5568-5577.
Vidwans SJ, Ireton K and Grossman AD (1995) Possible role for the essential GTP-binding protein Obg in regulating the initiation of sporulation in Bacillus subtilis. J Bacteriol 177:3308-3311.

Westberg J, Persson A, Holmberg A, Goesmann A, Lundeberg J, Johansson KE, Pettersson B and Uhlen M (2004) The genome sequence of Mycoplasma mycoides subsp. mycoides $\mathrm{SC}$ type strain $\mathrm{PG}^{\mathrm{T}}$, the causative agent of contagious bovine pleuropneumonia (CBPP). Genome Res 14:221-227.

Zalacain M, Biswas S, Ingraham KA, Ambrad J, Bryant A, Chalker AF, Iordanescu S, Fan J, Fan F, Lunsford RD, O'Dwyer K, Palmer LM, So C, Sylvester D, Volker C, Warren P, McDevitt D, Brown JR, Holmes DJ and Burnham MK (2003) A global approach to identify novel broad-spectrum antibacterial targets among proteins of unknown function. J Mol Microbiol Biotechnol 6:109-126.

\section{Internet Resources}

M. synoviae complete genome database, http://www.brgene.lncc. br/finalMS/.

M. hyopneumoniae strain J and M. hyopneumoniae strains 7448 complete genome databases, http://www.genesul.lncc.br.

BLAST tools, http://www.ncbi.nlm.nih.gov/blast.

Database of protein families (Pfam), http://www.sanger.ac.uk/ Software/Pfam/.

InterProScan software, http://www.ebi.ac.uk/InterProScan/. Associate Editor: Darcy F. de Almeida 